
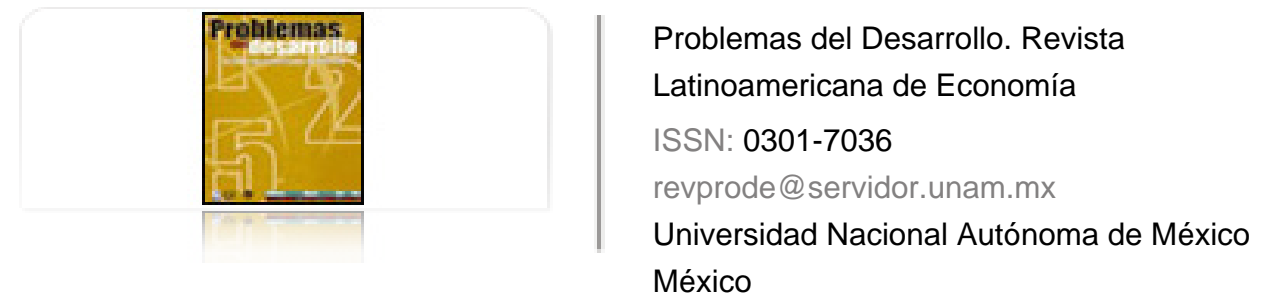

Gaulard, Mylène

Balance sobre la cuestión de las desigualdades en Brasil

Problemas del Desarrollo. Revista Latinoamericana de Economía, vol. 42, núm. 166, julio-septiembre, 2011, pp. 111-134

Universidad Nacional Autónoma de México

Distrito Federal, México

Disponible en: http://www.redalyc.org/articulo.oa?id=11819777006

Cómo citar el artículo

- Número completo

- Más información del artículo

Página de la revista en redalyc.org

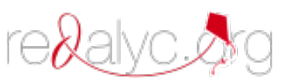

Sistema de Información Científica

Red de Revistas Científicas de América Latina, el Caribe, España y Portugal Proyecto académico sin fines de lucro, desarrollado bajo la iniciativa de acceso abierto 


\title{
BALANCE SOBRE LA CUESTIÓN DE LAS DESIGUALDADES EN BRASIL
}

\author{
Mylène Gaulard*
}

Fecha de recepción: 6 de enero de 2011. Fecha de aceptación: 11 de abril de 2011.

\begin{abstract}
RESUMEN
Después de que lo tildaron durante mucho tiempo de ser uno de los países más desigualitarios del mundo, Brasil experimenta desde la segunda mitad de los años noventa del siglo pasado una disminución de sus desigualdades de ingresos. Esta evolución es el resultado del proceso de "desindustrialización relativa" en el cual entró este país a finales de los ańos ochenta y no una consecuencia de las políticas económicas que emprendió el gobierno de Lula. Al contrario de lo que se podía suponer, la aparición de una nueva clase media tampoco constituye necesariamente una oportunidad para el crecimiento económico de Brasil.
\end{abstract}

Palabras clave: desigualdades, ingresos, políticas sociales, desindustrialización, Brasil.

\section{THE BALANCE OF THE QUESTION ON INEQUALITIES IN BRAZIL}

\begin{abstract}
After having been branded for a long time as one of the most unequal countries in the world, Brazil has experienced a reduction in its income inequalities since the second half of the 1990s. This has been a result of the "relative de-industrialization" process which this country entered at the end of the 1980s and not a consequence of the economic policies of the Lula Administration. Contrary to what may be supposed, the appearance of a new middle class also does not necessarily constitute an opportunity for economic growth in Brazil.
\end{abstract}

Key words: inequalities, incomes, social policies, de-industrialization, Brazil.

* Profesora-investigadora de la Escuela de Ingeniería en Agro-desarrollo Internacional (ISTOM). Correo electrónico: gaulard@netcourrier.com 


\section{BILAN SUR LA QUESTION DES INEGALITES AU BRESIL}

\section{Résumé}

Après avoir été longtemps dénoncé comme l'un des pays les plus inégalitaires au monde, le Brésil connaît depuis la seconde moitié des années 1990 une diminution de ses inégalités de revenus. Cette évolution est le résultat du processus de « désindustrialisation relative» dans lequel est entré le pays depuis la fin des années 1980, et non une conséquence des politiques économiques menées par le gouvernement Lula. Contrairement à ce qui aurait pu être supposé, l'apparition d'une nouvelle classe moyenne n'est pas non plus forcément une opportunité pour la croissance économique brésilienne.

Mots-clés : Inégalités, Revenus, Politiques sociales, Désindustrialisation, Brésil

\section{BALANCE SOBRE A QUESTÁO DAS DESIGUALDADES NO BRASIL}

\section{Resumo}

Depois de que se considerara durante muito tempo ser um dos países mais desiguais do mundo, Brasil experimenta desde a segunda metade nos anos noventa do século passado uma diminuição da sua desigualdade de renda. Esta evolução é o resultado do processo de "desindustrialização relativa" no qual entrou este país a partir de finais doa anos oitenta e não uma conseqüência das políticas econômicas empreendidas pelo governo Lula. Ao contrario do que se podia supor, a aparição de uma nova classe media também não constitui necessariamente uma oportunidade par ao crescimento econômico do Brasil Palavras-chave: desigualdades, renda, políticas sociais, desindustrialização, Brasil.

\section{巴西不平等问题的变化}

小结

在很多年中都被扣着是世界上最不平等的国家之一的帽子之后, 巴西从上 个世界九十年代的后半期起降低了它的不平等性。这种演变是“相对的非 工业化” 在八十年代末进入巴西的结果, 而不是卢拉政府实施的经济政策 的结果。相反的, 可以设想一下, 一个新的中产阶级的出现也不能有效地 为巴西的经济增长创立机遇。

关键词：不平等，收入，社会政策，非工业化，巴西 


\section{INTRODUCCIÓN}

Brasil se ubica hoy en día entre los diez países más desigualitarios ${ }^{1}$ del mundo, con un Índice $\mathrm{Gini}^{2}$ superior al 0.50. En los años ochenta del siglo pasado, el país llegaba en segunda posición, inmediatamente después de Sierra Leona. En realidad, el nivel de las desigualdades casi no dejó de aumentar desde los años setenta hasta la década de los noventa. Sin embargo, la particularidad de este país es que la evolución de las desigualdades se caracteriza por marcar un declive desde mediados de los noventa. El Índice Gini pasó así de 0.604 en 1994 a 0.53 en 2009 (datos Ipeadata). En ningún otro país se observó tan importante baja, y este tema es crucial para el próximo gobierno. ¿¿Son realmente Lula y el PT-cuyas políticas sociales se consideran hoy como el origen de este avance del país hacia una sociedad más justa- los causantes de esta disminución de las desigualdades? ¿Puede la ganadora de la última elección presidencial, Dilma Roussef, reivindicar legítimamente este balance positivo por ser miembro del PT? Se tratará aquí de cuestionar la validez de los datos sobre la disminución de las desigualdades y luego de estudiar las causas y las consecuencias de esta evolución.

\section{LA EVOLUCIÓN RECIENTE DE LAS DESIGUALDADES EN BRASIL}

\section{La formación de un país desigualitario}

Para aprehender mejor la evolución reciente de las desigualdades en Brasil, en primer lugar es indispensable comprender las razones de la formación de una de las estructuras socioeconómicas más desigualitarias del mundo. Asimismo, las particularidades de la colonización de Brasil generaron, desde el siglo XvI, una importante desigualdad en la propiedad de la tierra que se ha mantenido hasta hoy en día.

Portugal estableció progresivamente quince capitanías hasta 1532 a fin de organizar el territorio y explotar de manera racional los pocos recursos naturales

1 Después de Bolivia, Botsuana, República Centro Africana, Guatemala, Haití, Lesoto, Namibia, Suráfrica y Zimbabue (según la Oficina de Estadísticas de Naciones Unidas) (World Income Inequality Database).

2 Índice Gini: índice del grado de concentración de las riquezas, en una escala de 0 a 1; entre más cerca esté de 1, las desigualdades son más importantes. 
que se encontraban en él. Cada una de estas capitanías era dirigida por un donatorio que poseía el $20 \%$ de su superficie, siendo concedido el resto a colonos en forma de sesmarias, lotes de tierras destinados al desarrollo de la agricultura y la ganadería. Estos donatorios recibieron de la corona portuguesa el encargo de colonizar su área en un plazo de cinco años con el respaldo de colonos. Este modo de organización fue la causa directa de la estructura agraria actual de Brasil, marcada por una gran concentración de las tierras y el peso político muy marcado de los grandes terratenientes brasileños, los fazendeiros.

\section{El reforzamiento de la estructura desigualitaria de Brasil durante la dictadura militar}

Sin embargo, el carácter desigualitario de la sociedad se acentuó sobre todo durante la dictadura militar (1964-1985) y durante la crisis económica que azotó el país hasta mediados de la década de los noventa. Efectivamente, se reforzó ampliamente la intensidad de capital con la llegada de los militares al poder en 1964 puesto que estos últimos deseaban modernizar el aparato productivo nacional, y la evolución de la industria hacia una mayor producción de bienes de consumo durables dio origen a un fuerte aumento de la demanda de trabajadores capacitados en detrimento de la demanda de mano de obra sin capacitación. Las políticas emprendidas por los militares consistían en fomentar exportaciones y en favorecer el incremento de las desigualdades de ingreso a fin de elevar la parte del mercado interior que pudiera consumir bienes durables denominados "de lujo". Mientras que el salario mínimo real pasaba de 85374 cruzeiros en 1964 a 54405 cruzeiros en 1965 (Bresser Pereira, 1977: 67), una "tercera demanda” emergía progresivamente entre los trabajadores capacitados gracias al alza de sus ingresos.

Entre 1960 y 1970, la parte del ingreso nacional correspondiente al 50\% más pobre de la población se redujo del $17.4 \%$ al $14.9 \%$, mientras que la del 10\% más rico creció del 39.6\% al 46.7\% (Serra, 1982: 64). Mientras se mantenían los salarios de la gran mayoría en un nivel bajo, se pudo incrementar los sueldos de los trabajadores más capacitados, en términos reales, a fin de permitir el crecimiento de un mercado privilegiado para evitar los problemas de sobreproducción. Esta evolución se vio reforzada por la financiarización de la economía, fenómeno observado desde finales de la década de los años setenta, y por el incremento de los ingresos financieros, debido a las tasas de interés elevadas y al ajustamiento de los ingresos a la inflación, los cuales benefician a las categorías acomodadas de la población. En consecuencia, el grado de desigualdad se 
mantiene alto desde la década de los sesenta, con un Índice Gini que se avecina al 0.60 y que aumentó con la desaceleración del crecimiento económico de la década de los ochenta, de 0.585 en 1981 a 0.635 en 1989 (datos Ipeadata).

\section{La expansión de las desigualdades durante la desaceleración económica de los años ochenta}

Mientras que los ingresos provenientes de la finanza crecieron considerablemente, la fuerte productividad del trabajo generó un incremento del desempleo y una expansión sin precedente del sector informal durante la desaceleración económica, de la década de los ochenta hasta mediados de los noventa. La tasa de desempleo pasó del 5\% al 9\% entre 1980 y 1985, y eso que esta cifra sólo toma en cuenta los trabajadores de nómina en el sector formal que representaban solamente el 50\% de la población activa (datos Ipeadata). En las grandes ciudades, los empleos informales constituyeron así el 87\% de los empleos creados entre 1990 y 1995. Esta presión ejercida sobre el mercado del trabajo fue la causa de una fuerte caída de los sueldos: el salario real promedio anual disminuyó considerablemente entre 1990 y 1996, de 9203 a 4789 dólares (Mesquita Moreira, 2006). En consecuencia, la proporción de pobres en la población -los brasileños cuyo ingreso es inferior a la mitad del salario mínimo- se elevó del 39\% al $43 \%$ entre 1977 y 1993 , pasando aun por un pico del 49\% en 1983. Asimismo, la gente en situación de extrema pobreza (menos de una cuarta parte del salario mínimo) constituía el 16\% de la población en 1977, frente al 20\% en 1993 (el $23 \%$ en 1983) (datos Ipeadata).

Durante toda la segunda mitad del siglo xx, Brasil experimentó por lo tanto un incremento de sus desigualdades, evolución que coincidió con un distanciamiento entre el sur y el norte del país. Actualmente, con el $43 \%$ de la población nacional, el Sudeste realiza el 59\% del PIB, frente al 13\% solamente para el Nordeste que concentra el 29\% de la población (datos Ipeadata). Las regiones del sur del país representan el bastión de la agricultura y la industria brasileñas mientras que se ignoraban regiones como el Nordeste hasta hace poco. Aun cuando los diferentes gobiernos intentaron incitar a las empresas para que se instalaran en las regiones pobres del país (por ejemplo, con la creación en 1959 de la Sudene, Surintendencia de Desarrollo del Nordeste), las industrias con mejor desempeño se han instalado sobre todo en el sur para disponer de infraestructuras y colocarse en economías de escala y de aglomeración (Théry, 2000: 230-235). Por otra parte, además de la presencia de grandes propiedades agrícolas y de fazendas a veces destinadas exclusivamente a la ganadería, el Nordeste 
se ha caracterizado por la presencia de numerosas pequeñas explotaciones que no se pueden hacer fructificar debido a la falta de recursos económicos.

La degradación de las condiciones de vida en el campo -relacionada con la falta de rentabilidad de las pequeñas extensiones agrícolas y la expulsión de los pequeños propietarios- dio origen durante mucho tiempo a un éxodo rural masivo. Si bien este éxodo ya no es realmente un tema actual en Brasil -ya que la población es urbana en un $80 \%$ ( $70 \%$ en el Nordeste) - no se puede eludir que, hasta los años noventa, las migraciones se efectuaban principalmente desde las regiones del norte agrícola hacia el Sudeste industrial. Hoy en día, el estudio de las desigualdades interregionales sigue oponiendo regiones donde domina la agricultura a regiones donde domina la industria. En 2009, el Nordeste reunía el $46 \%$ de los brasileńos considerados como pobres por el Banco Mundial (ingreso inferior a 1 dólar por día), aunque sólo el 30\% de la población brasileña se encuentra en esta región.

\section{La disminución reciente de las desigualdades}

\section{La disminución de las desigualdades regionales}

Sin embargo, el caso de Brasil presenta una evolución interesante, puesto que las desigualdades regionales tienden a disminuir desde finales de los años noventa. La expansión sin precedente de la actividad agrícola devuelve un peso importante en la economía brasileña a las zonas rurales anteriormente desdeñadas. Mientras que las materias primas no constituían más que el $20 \%$ de las exportaciones brasileñas a inicios de los años noventa, hoy en día representan el 50\%. Los sectores agrícola y minero tienden a aumentar la riqueza de estas regiones, y estimulan también en ellas la expansión del sector agroalimentario. Una región como el Nordeste, cuya población es urbana en un 70\% (cuando los citadinos constituyen el $90 \%$ en el sur y el Sudeste), ha experimentado un fuerte incremento de sus exportaciones (del 18.57\% entre 2000 y 2004, mientras que fue del $16.05 \%$ al nivel nacional) (datos Ipeadata). Esta evolución tiene su explicación no sólo en el peso creciente de las exportaciones agrícolas, sino también en el hecho de que las regiones más pobres establecen medidas para atraer a las empresas (Oman, 2000: 35). Las actividades productivas (en particular las que están relacionadas con las industrias de mano de obra tradicionales del sector de los bienes de consumo, tales como los textiles, los insumos alimenticios, las bebidas, la higiene y los productos de limpieza) han ido dejando el sur del país para instalarse en el norte, el noreste y el centro oeste. Por ende, la pobreza 
tiende actualmente a disminuir en las regiones anteriormente apartadas del proceso de crecimiento; por ejemplo, en el Nordeste, pasó del 65\% de la población en 1988 al 34\% en 2008 (datos Ipeadata).

Gráfica 1. Evolución del Índice Gini en Brasil (1978-2009)

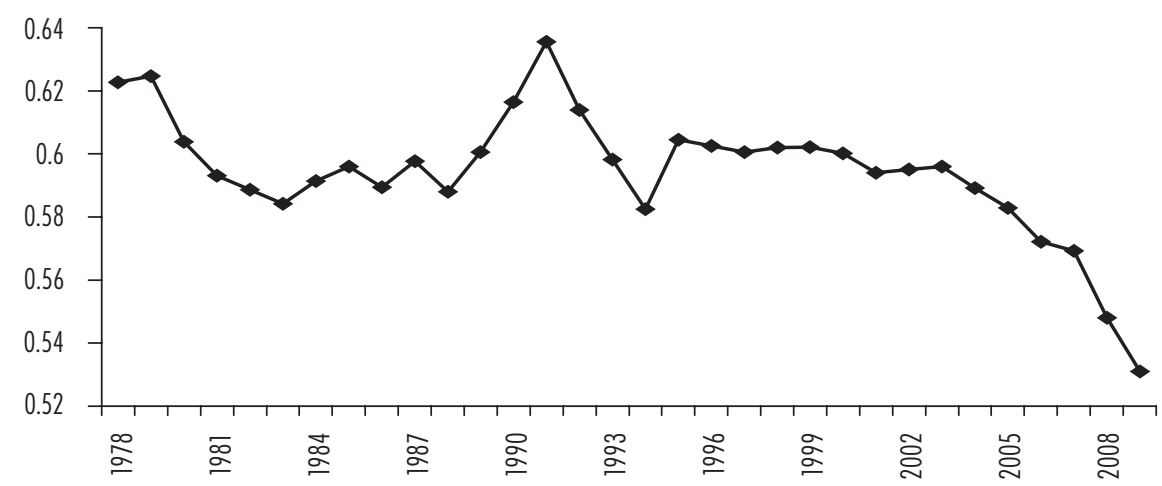

Fuente: Ipeadata, gráfica realizada por el autor.

\section{La disminución de las desigualdades de ingreso al nivel nacional}

Esta disminución de las desigualdades no sólo se observa al nivel regional ya que, después de confrontarse a un aumento de sus desigualdades de ingreso que lo colocó entre los países más desigualitarios del mundo, Brasil experimenta desde hace poco una ligera reducción de éstas, alcanzando un Índice Gini de 0.53 en 2009. La parte en el ingreso del 1\% más rico de la población pasó del 13.1\% al $12.8 \%$ entre 2000 y 2009 , mientras que la del $50 \%$ más pobre subió durante el mismo periodo del $13.3 \%$ al $15.6 \%$. Sin embargo, si bien es cierto que numerosos trabajos, como los de Paes de Barros $(2007 ; 2010)$, recalcan que las disparidades de ingreso disminuyen en Brasil, no quita que éstos son enérgicamente impugnados, en particular por un autor como Pochmann (2003), quien nota que una parte siempre mayor de los ingresos obtenidos por las clases privilegiadas proviene de la esfera financiera y no son contabilizados por el IPEA (Instituto de Investigaciones en Economía Aplicada) del gobierno: los ingresos del trabajo ya sólo constituyen, en 2009, el 35\% del conjunto de éstos con los ingresos por las tasas de interés y los beneficios, frente al 52\% en 1990. Parece ser entonces 
que se subestimaron los ingresos de estas clases, y por ende, que se subestimaron las desigualdades (Dedecca, 2008).

Esta crítica de Pochmann fue puesta en duda recientemente por un estudio de Paes de Barros (2007b) que, tomando esta vez en cuenta todas las fuentes de ingresos y recurriendo a nuevas encuestas, concluye nuevamente que se presenció una baja de las desigualdades ya en los noventa. Desde la década del 2000, los ingresos financieros sufren efectivamente una ligera baja: los ingresos de la propiedad (intereses y dividendos) cayeron así del $4.5 \%$ del ingreso nacional en 2002 al 3\% en 2009 (datos Ipeadata).

Paralelamente a esta reducción de las desigualdades, también es importante resaltar la fuerte disminución de la pobreza (Rocha, 2011). La tasa de pobreza, que corresponde a las personas que se encuentran abajo del umbral de pobreza -el cual varía según las regiones pero presenta ahora un promedio nacional de 175.15 reales (76 euros) por mes- cayó así del 43\% de la población en 1993 al $22.5 \%$ en 2008 . Asimismo, la tasa de pobreza extrema, que contabiliza la

Gráfica 2. Ingreso promedio de las seis decilas más pobres de la población brasileña en porcentaje del ingreso mensual promedio nacional

(1980-2009)

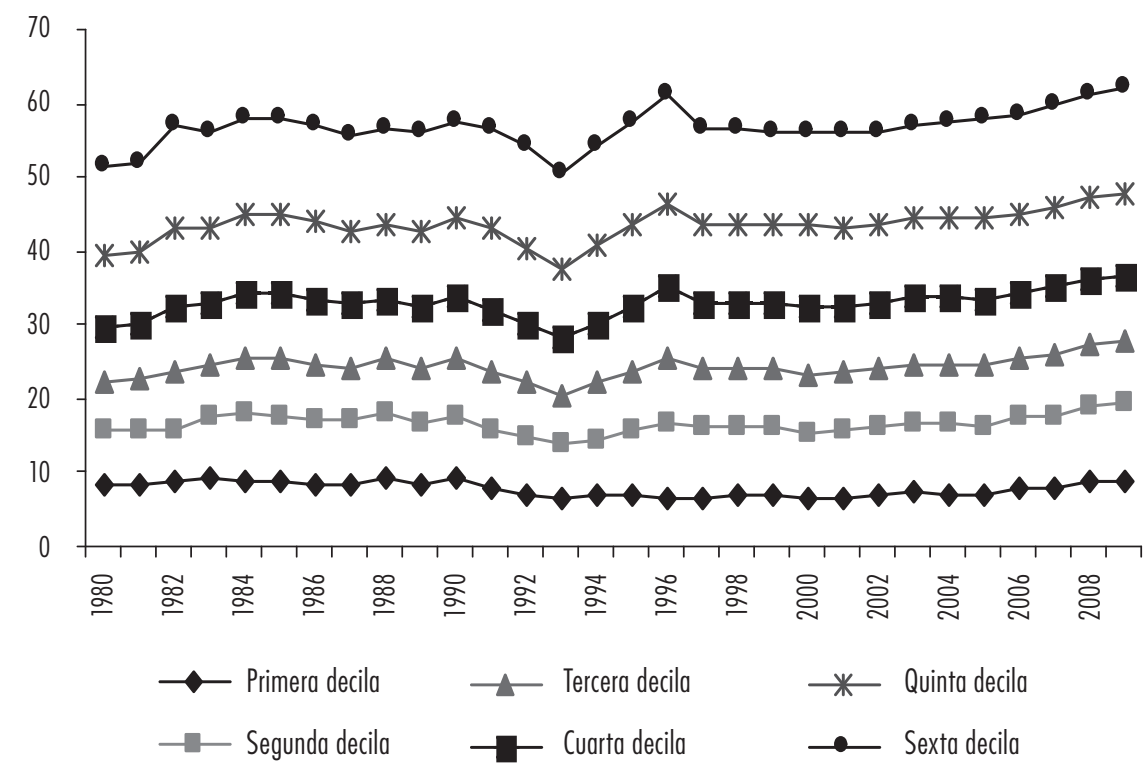

Fuente: Ipeadata, gráfica realizada por el autor. 
Gráfica 3. Ingreso promedio de la decila más rica de la población brasileña en porcentaje del ingreso mensual promedio nacional

(1980-2009)

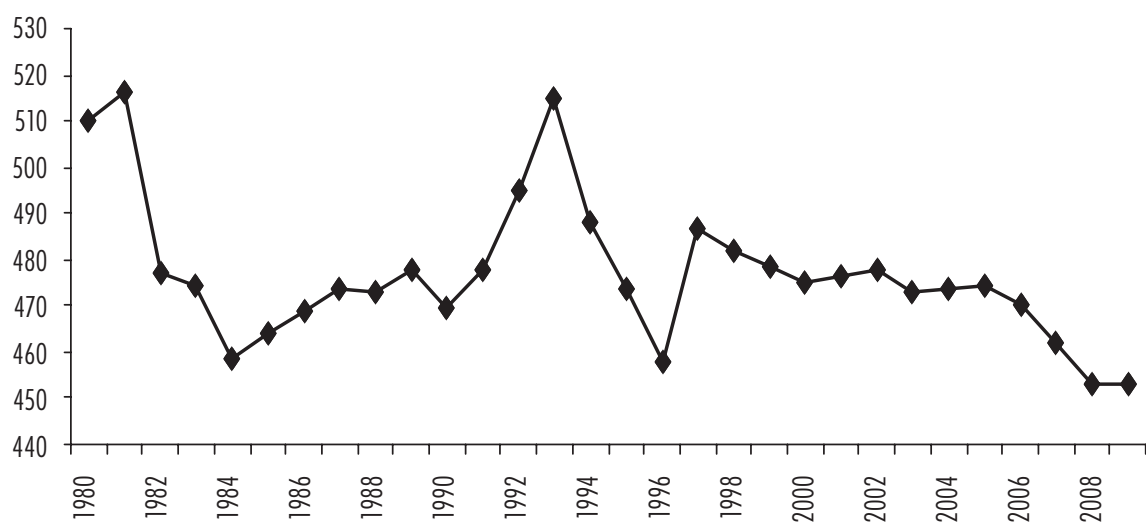

Fuente : Ipeadata, gráfica realizada por el autor.

población que se encuentra abajo del umbral de extrema pobreza, el cual corresponde en promedio a 87.57 reales (38 euros), pasó del 20\% al 7.5\% entre 1993 y 2008 (datos Ipeadata).

\section{LAS CAUSAS DE LA DISMINUCIÓN DE LAS DESIGUALDADES}

\section{La eficacia de las políticas económicas}

\section{Las politicas de lucha contra la inflación}

Tal disminución de las desigualdades y de la pobreza podría interpretarse como la consecuencia de las políticas económicas emprendidas a favor de los pobres por el gobierno de Cardoso, pero sobre todo por el presidente Lula desde 2002. Según el IPEA, mientras estas políticas se mantienen, el Gini podría alcanzar 0.49 y la extrema pobreza ser totalmente erradicada de aquí a 2016.

La primera causa, y la más obvia, de la baja de las desigualdades desde 1994 parece ser la evolución de la inflación y las políticas instauradas para luchar contra el alza de los precios. Efectivamente, la tasa de inflación cayó repentinamente en 1994 (gracias a las medidas establecidas por el Plan Real), año a partir del 


\section{Mylène Gaulard}

Gráfica 4. Pronóstico de la evolución de las desigualdades y de la pobreza en Brasil

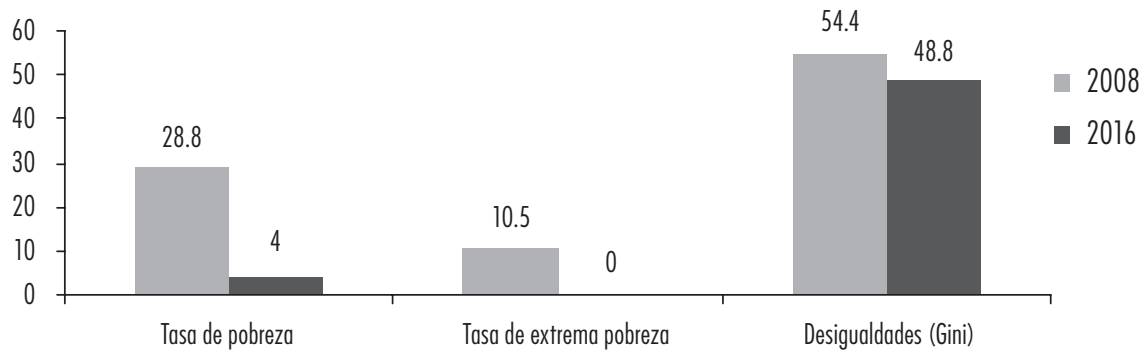

Fuente: Ipeadata.

cual el Índice Gini empezó a disminuir. Asimismo, entre 1994 y 1996, la tasa de inflación IPCA ${ }^{3}$ pasó del $916.46 \%$ al 9.56\%, mientras que el Gini bajó ligeramente, de 0.605 a 0.602 .

Cuadro 1. Tasa de inflación (en \%)

\begin{tabular}{rrrrrr}
\hline 1980 & 99,2 & 1990 & 1621 & 2000 & 6 \\
1981 & 95,6 & 1991 & 472,7 & 2001 & 7,7 \\
1982 & 104,8 & 1992 & 1119,1 & 2002 & 12,5 \\
1983 & 164 & 1993 & 2477,1 & 2003 & 9,3 \\
1984 & 215,3 & 1994 & 916,5 & 2004 & 7,6 \\
1985 & 242,2 & 1995 & 22,4 & 2005 & 5,7 \\
1986 & 79,7 & 1996 & 9,6 & 2006 & 3,1 \\
1987 & 363,4 & 1997 & 5,2 & 2007 & 4,5 \\
1988 & 980,2 & 1998 & 1,7 & 2008 & 5,9 \\
1989 & 1972,9 & 1999 & 8,9 & 2009 & 4,3 \\
\hline
\end{tabular}

Fuente : Ipeadata, tasa de inflación IPCA

Existe efectivamente un fuerte vínculo entre desigualdades e inflación, ya que las categorías más acomodadas de la población tienen los medios para preservar sus ingresos y ajustar una parte importante de éstos a esta alza de los

3 Tomamos aquí el índice IPCA, índice que refleja la evolución del coste de la vida, es decir de una canasta de bienes de consumo para una familia con un ingreso de 1 a 40 sueldos mínimos, en las nueve regiones metropolitanas más grandes del país (Sao Paulo, Rio de Janeiro, Belo Horizonte, Salvador, Porto Alegre, Recife, Brasilia, Fortaleza, Belem). 
precios, mientras que los más pobres, cuya remuneración no se eleva tan rápido como los precios, experimentan la caída de su sueldo. El dispositivo de corrección monetaria instituido durante la dictadura militar, que ajusta el valor de los activos financieros a la inflación, dio así origen a un fuerte aumento de las desigualdades durante la década de los ochenta, puesto que el alza de los precios pesa sobre el poder adquisitivo de los asalariados y no sobre el de los rentistas. Al contrario, la caída de esta inflación a partir de 1994 fue un tanto favorable a los asalariados. Sin embargo, mientras que la reducción de la tasa de inflación fue extremadamente brusca entre 1994 y 1996, la disminución del Índice Gini fue muy leve. Sobre todo, el Índice Gini no ha dejado de disminuir desde finales de la década de los noventa, mientras que la inflación se ha quedado estable y se ha mantenido entre el 2\% y el 12\% (incluso subió esta tasa entre 1998 y 1999 , y luego entre 2000 y 2002, sin embargo el Gini seguía disminuyendo). Por lo tanto es necesario encontrar otras explicaciones que la evolución de los precios a la disminución de las desigualdades.

\section{El papel de las políticas sociales}

La eficacia de las políticas sociales emprendidas o desarrolladas durante la presidencia de Lula se resalta muchas veces para explicar esta evolución de las desigualdades. Es innegable, en particular, que la fuerte revalorización del salario mínimo actuó mucho a favor de los trabajadores sin capacitación. Entre 2003 y 2010, pasó de 240 a 510 reales, lo cual no sólo incrementó el ingreso del $25 \%$ de la población activa que percibe el salario mínimo (así como el de los demás trabajadores que está relacionado con su evolución), sino que, sobre todo, elevó los gastos sociales del Estado (el 65\% de los gastos de seguro social-como por ejemplo las prestaciones pagadas en caso de desempleo y, sobre todo, las pensiones de retiro- se ajustan al salario mínimo).

Según Paes de Barros (2007c) el 25\% de la disminución de las desigualdades tiene su explicación en las transferencias sociales, aunque estas últimas sólo representan el 20\% de los ingresos; en cambio, "sólo" el 50\% de la disminución de las desigualdades es atribuible a la evolución de los ingresos del trabajo (que representan el $80 \%$ de los ingresos). Asimismo, el ingreso promedio de los trabajadores que forman parte del 10\% más pobre de la población pasó de 96 a 58 reales entre 1995 y 2004, y mientras que en 1995 el 89\% de los ingresos de esta población provenía de la remuneración del trabajo, esta parte ya sólo constituía el 48\% en 2004 (Marques y Nakatani, 2007). Esta evolución tiene su explicación en la extensión de las políticas sociales y de ayudas dirigidas a los más pobres que se 
profundizaron bajo el mandato presidencial de Lula. Por ejemplo, la política social más mediatizada en Brasil es la Beca Familiar (lanzada en 2003), programa de transferencia de ingresos hacia las familias que se encuentran abajo del umbral de pobreza. Este programa permite otorgar cada mes entre 62 reales (23.7 euros) y 182 reales (70 euros) a las familias más pobres a condición de que continúen escolarizando y vacunando a sus hijos. Concierne hoy en día el 25\% de la población brasileña (12 millones de familias); en 2009, esta gente recibió 8.2 billones de reales, lo que corresponde al $0.4 \%$ del piB. Asimismo, se analizó que para las regiones más pobres, en particular el Nordeste, la Beca Familiar jugó un papel importante en la disminución de las desigualdades durante la década del 2000 (Hoffmann, 2007; Cacciamali y Camillo, 2009a; Rocha, 2011).

La Beca Familiar forma parte de los cash transfers (entrega de dinero a las familias más pobres, en condiciones precisas) cuyos méritos ponderan las grandes instituciones internacionales como el Banco Mundial y el FMI, pero que se acusa muchas veces de ser nuevas formas de paternalismo. Es extremadamente mediatizada pero no es el último programa social que influye sobre el nivel de pobreza; otras medidas, instauradas desde la década de los noventa (Lautier, 2007), antes de la llegada de Lula al poder, contribuyen igualmente a luchar contra la pobreza y las desigualdades. Por ejemplo, el programa creado en 1996 de Beneficio de Prestación Continua (BPC), que otorga una prestación económica a las personas mayores o discapacitadas cuyo ingreso es inferior a una cuarta parte del salario mínimo, concierne solamente a tres millones de personas pero representa el 0.6\% del рів (frente al 0.4\% para la Beca Familiar) (Rocha, 2011).

No se puede eludir que el peso de estos cash transfers crece a expensas de los demás gastos, menos mediatizados, y a la inversa de lo que muchos creen, no aumentaron realmente los gastos sociales del gobierno bajo el mandato de Lula; al contrario, los gastos de seguro social (que reúnen los gastos de salud, de asistencia social y de protección de los trabajadores) pasaron del $40 \%$ del presupuesto de la Unión en 2003 al 35\% en 2009 (datos Ipeadata).

\section{Los factores estructurales de la disminución de las desigualdades}

\section{Un cuestionamiento del papel de las políticas económicas en la lucha contra las desigualdades}

Los gastos sociales, cuyo peso en el presupuesto público no deja de disminuir, no se pueden considerar, por ende, como la única causa de la disminución de las desigualdades. Tanto más es sustentable esta afirmación cuanto que los cash transfers 
sólo conciernen la categoría del 25\% más pobre de la población aunque los que la conforman no son quienes se benefician mayoritariamente con el alza de los ingresos de los brasileños menos acomodados. A continuación, el Cuadro 2 nos revela efectivamente que entre el $50 \%$ más pobre de la población, la capa del 30\% que disfruta los ingresos menos bajos es la que más se beneficia con la baja de las desigualdades. Entre 2000 y 2009, mientras que el ingreso del 20\% más pobre de la población pasó del $3.5 \%$ al $3.8 \%$ del ingreso nacional, la parte del $50 \%$ más pobre se elevó del $13.3 \%$ al $15.6 \%$. No son los brasileños que más sufren la pobreza quienes se benefician realmente con esta estructura igualitaria, lo cual parece demostrar que las políticas sociales de Lula, que se suponen dirigidas a la cuarta parte más pobre de la población, no determinaron por sí solas la situación actual.

Cuadro 2. Parte de las diferentes capas de ingreso en el ingreso nacional brasileño, en porcentaje (1960-2009)

\begin{tabular}{lrrrrrrrr}
\hline & 1960 & 1970 & 1980 & 1985 & 1990 & 1995 & 2000 & 2009 \\
\hline 20\% más pobre & 3.9 & 3.4 & 2.8 & 2.3 & 2.7 & 2.6 & 3.5 & 3.8 \\
50\% más pobre & 17.4 & 14.9 & 12.6 & 13.5 & 14.1 & 12 & 13.3 & 15.6 \\
$20 \%$ más rico & 55.7 & 63.8 & 64.6 & 63.9 & 63.5 & 63.2 & 62.6 & 62.1 \\
$10 \%$ más rico & 39.6 & 46.7 & 50.9 & 47.3 & 48.1 & 47.1 & 45.9 & 44.4 \\
$5 \%$ más rico & 28.3 & 34.1 & 37.9 & 35.8 & 36.2 & 35.3 & 33.2 & 31.7 \\
1\% más rico & 11.9 & 14.7 & 16.9 & 14 & 13.9 & 13.4 & 13.1 & 12.3 \\
\hline
\end{tabular}

Fuente: Ipeadata.

No parece que fuera de estas ayudas extremadamente selectivas, el gobierno de Lula haya emprendido una real política social que explicara por sí sola la disminución de las desigualdades. Al contrario, la mayor parte de las políticas económicas de su gobierno tendieron más bien a agravarlas. La política presupuestal de Lula tuvo como principal propósito conseguir un excedente primario para satisfacer los criterios de responsabilidad de los grandes organismos económicos internacionales, y la deuda neta del sector publico pasó del $57.2 \%$ del PIB en 2003 al 43\% en 2009 (datos Ipeadata). Esta mejora de las cuentas del Estado se efectuó mediante un incremento del excedente primario -o diferencia entre las recetas y los gastos del ańo, pago de los intereses de la deuda excluido- ya que pasó del $4.25 \%$ en 2003 al $4.84 \%$ en $2005 .{ }^{4}$ Por supuesto, este excedente

4 En 2009, el excedente primario bajó al 3.98\% del PIB a raíz de la ligera contracción de la actividad económica. 
primario se obtuvo esencialmente disminuyendo la mayor parte de los gastos sociales. En 2009, mientras que la carga de la deuda constituía el 37\% de los gastos del Estado, el seguro social de los brasileños sólo absorbía el 35\% de éstos frente al 40\% en 2003 (datos Ipeadata).

En lo concerniente a la política fiscal, es innegable que los más pobres se han visto perjudicados también por una política de impuestos decrecientes. Los más altos ingresos son proporcionalmente menos gravados que los más bajos. Esto tiene su explicación esencialmente en la importancia de los impuestos indirectos. La carga fiscal representaba en 1980 el 22\% del PIB, frente al 35\% en 2009 (datos del Banco Central). Ahora bien, el impuesto brasileño se compone esencialmente de impuestos indirectos, que atañen tanto a los más pobres como a los más ricos, sea cual sea el nivel de su ingreso, lo cual les confiere un carácter regresivo e "injusto". Asimismo, el 65\% del impuesto brasileño se recauda del trabajo asalariado y del consumo. En promedio, la carga tributaria nacional se incrementó del $20.6 \%$ en los últimos 10 años, mientras que para el $10 \%$ más rico de la población, esta alza sólo fue del $8.4 \%$ (el 10\% más pobre gasta el 33\% de sus ingresos en impuestos, frente al 23\% para el 10\% más rico) (Pochmann, 2008).

Si bien es cierto que las categorías más ricas de la población brasileña no son más gravadas que las más pobres, se benefician también mucho del presupuesto del Estado. Los gastos públicos incrementan así en mayor medida los ingresos de los más ricos, tal como lo revelan los trabajos de Neri (2007): las transferencias vinculadas con la previdência (vejez, enfermedad, desempleo) representan el $16.2 \%$ del ingreso promedio del $50 \%$ más pobre de la población, frente al $19.6 \%$ para el conjunto de la población, y el 18.9\% para el 10\% más rico. Esto tiene su explicación esencialmente en el hecho de que los más ricos tienen una mejor protección social (Hoffmann, 2009). Fue sólo gracias a recientes programas sociales extremadamente focalizados que, finalmente, las transferencias públicas pasaron a privilegiar ahora un poco más el $50 \%$ más pobre (Neri, 2007).

En cuanto a la política monetaria del gobierno de Lula, ha sido probablemente la política económica que más se vio señalada. Consistió en mantener tasas de interés extremadamente altas a fin de seguir financiando la deuda pública. La tasa Selic de corto plazo alcanzó en julio de 2010 el 10.25\%, lo cual, por supuesto, ha tenido incidencia en las tasas de plazos largos cuyo spread rebasa muchas veces el 30\% (datos del Banco Central). Ahora bien, es cierto que estas tasas de interés penalizan la inversión y por ende el crecimiento, favorecen sobre todo el enriquecimiento de los ricos. La compra de títulos financieros, y en particular de bonos del Tesoro, incrementa el patrimonio de 
estos hogares. Asimismo, los brasileños más acomodados han acostumbrado invertir una parte importante de sus ingresos en la esfera financiera: según Pochmann (2003), el 5\% más rico (con ingresos superiores a treinta veces el salario mínimo) gasta una cuarta parte de sus ingresos en la compra de bienes que aumentan el valor de su patrimonio, frente al $4.5 \%$ para los más pobres (con ingresos inferiores a dos sueldos mínimos). Los cinco bancos más grandes de Brasil concentrarían así el 69\% de los beneficios del sistema bancario, el $50 \%$ de sus beneficios provendrían de títulos de la deuda pública y, en 2006, sólo 15000 familias poseían el 80\% de los títulos públicos federales (Armando Boito Junior, 2006).

\section{La evolución del mercado laboral}

Para un economista como Marcelo Neri (2007), en suma, las políticas económicas son menos determinantes que la evolución del mercado laboral brasileño para la disminución de las desigualdades. De igual forma, según Paes de Barros (2010), la disminución de la segmentación entre actividades y la reducción de las desigualdades de ingreso explicaría más del $50 \%$ de la evolución del Gini. A raíz de la desindustrialización, la orientación del aparato productivo brasileño hacia la producción de bienes de bajo tenor tecnológico y fuerte intensidad de trabajo permite emplear más trabajadores sin capacitación que los que hubieran podido serlo con el patrón anterior de elevación constante de la intensidad de capital (Kliass y Salama, 2007).

Asimismo, aunque Brasil ha vuelto a tener un fuerte crecimiento económico, del 7.5\% en 2010, su tasa de formación bruta de capital fijo se mantiene en un nivel muy bajo, inferior al 20\% del pIB (frente a casi el 50\% de China). La parte de la industria de transformación en el PIв cayó del 36\% en 1985 al 15.5\% en 2009 (Gaulard 2011: 106), lo cual revela un proceso de desindustrialización que, sin embargo, algunos economistas brasileńos ponen en entredicho (Nassif, 2008), aunque lo estudiaron y condenaron durante mucho tiempo autores como Bresser Pereira $(2008 ; 2009)$ o bien Oreiro y Feijó (2010). En realidad, esta evolución tiene su explicación en el fuerte crecimiento del sector de las materias primas. Éstas constituyeron el 50\% de las exportaciones en 2010 frente al 35\% en 2000 y en la disminución relativa del peso de los sectores industriales que más capital utilizan -las cuales representaban el 49.27\% de la producción nacional en 2009 frente al 53.74\% en 1996 (Gaulard, 2011: 107)- en beneficio de producciones que emplean más mano de obra. 
Según la OCDE, ${ }^{5}$ en el periodo 2000-2007, la elasticidad del empleo conforme al PIв fue mucho más baja en China (0.1) que en Brasil (1.2). A raíz de la evolución particular del aparato productivo y del interés puesto en sectores que emplean esencialmente mano de obra sin capacitación, se observa actualmente una disminución de la tasa de desempleo, que pasó del 10.5\% de la población activa en 2003 al 7.5\% en 2009, mientras que no había dejado de aumentar durante veinte años. La tasa de desempleo oculto (que registra también los trabajadores informales) se ha reabsorbido también considerablemente en la región de Sao Paulo, pasando del 20\% de la población activa en 2003 al 12\% en 2009 (datos Ipeadata). De igual manera, el trabajo informal cayó del $56.2 \%$ de la población activa en 1999 al 50.7\% en 2007, y 12 millones de puestos se crearon en el sector formal entre enero de 2003 y febrero de 2010 (datos Ipeadata). En consecuencia de una mayor oferta de trabajo que no precisa capacitación, mientras que se estanca la oferta de trabajo para trabajadores capacitados, los ingresos del trabajo de las cinco décimas más pobres de la población se elevaron entre 2001 y 2009 dos veces más rápido que los de las cuatro décimas siguientes, y tres veces más rápido que los de la décima más rica. Las desigualdades entre trabajadores con capacitación y sin capacitación han disminuido, pasando el Índice Gini para los ingresos del trabajo de 0.552 en 2003 a 0.515 en 2007 (Paes de Barros, 2007a).

Parece ser entonces que la política económica del gobierno brasileño explica mucho menos la disminución de las desigualdades observada desde mediados de la década de los noventa que la menor disparidad entre los ingresos del trabajo, lo cual confirman varios estudios brasileños (Hoffmann, 2007; Soares, 2007; Cacciamali y Camillo, 2009b). Insistir en estas transferencias sociales, y no en los cambios estructurales de la economía brasileña (disminución del trabajo informal, alza del salario mínimo, incremento del trabajo para mano de obra sin capacitación...), impide aprehender toda la complejidad de la evolución de las desigualdades brasileñas. Tal como lo afirma Claudio Salm (2007):

la Beca Familiar es un ejemplo de política que no interfiere directamente con el mercado y que, por lo tanto, debe ser promovida por el pensamiento ortodoxo, mientras que las alzas al sueldo mínimo (como institución universal) forman parte de una política que interfiere en la formación de un precio fundamental, el precio del trabajo, y por ende, pueden y deben ser ignoradas según esta corriente de pensamiento.

5 OCDE, Employment Outlook, 2007, p. 31. 


\section{EL PORVENIR DE LA SOCIEDAD BRASILEÑA}

\section{La desaparición de la "tercera demanda" en beneficio de una nueva clase media}

\section{La desaparición de la tercera demanda}

Pese a esta disminución de las desigualdades, algunos autores como Bresser Pereira (2009) insisten en sostener que observamos una polarización de la sociedad brasileña. La clase media, que constituye la tercera demanda del "milagro económico" (1968-1973), estaría en un proceso de pauperización. Por otra parte, el $2 \%$ más rico de la población estaría experimentando un incremento considerable de su fortuna. Asimismo, según la Folha de Sao Paulo del 13 de enero de 2008, la fortuna de los brasileños que poseen más de un millón de dólares creció del 22.4\% en 2007, el segundo mayor crecimiento del mundo justo después de China (23.4\%). Los millonarios (en dólares) pasaron así de 130000 personas en 2006 a 190000 en 2007, lo cual corresponde al 0.1\% de la población brasileña.

Ahora bien, en los años 1960-1970, no sólo el 0.1\% o el 2\% más rico se enriquecían, también la clase media o "tercera demanda" se beneficiaba con el aumento de las desigualdades que la oponían al $80 \%$ más pobre de la población. En el Brasil de los años sesenta, la producción de bienes de consumo durables destinados a las capas más acomodadas de la población generaba poca absorción de la mano de obra sin capacitación y el aumento de las capacidades de producción ociosas en las empresas. Sin embargo, el estancamiento económico fue evitado desde finales de los años sesenta gracias a la disminución de los salarios de los obreros y a la aparición de una "tercera demanda" vinculada con la multiplicación de los empleos para trabajadores capacitados. Ésta correspondía con la demanda de una amplia clase media, que constituía aproximadamente el 20\% de la población y se yuxtaponía al consumo del $5 \%$ más rico. Desde finales de los años sesenta hasta los años setenta, por ende, Brasil experimentó un periodo denominado de "milagro económico" que sostenía en parte el consumo de esta "tercera demanda".

Al contrario, desde finales de los años noventa, el Gini disminuye mientras que el volumen de los ingresos de la "tercera demanda" es siempre menor. Una clase media aparece actualmente pero, contradiciendo lo que se enuncia en el concepto de tercera demanda, ésta se avecina más a las categorías más pobres que a las más ricas. Efectivamente, la parte de las dos décimas más ricas en el ingreso nacional pasó del $63.9 \%$ al 62.1\% entre 1980 y 2009, mientras que la del $50 \%$ más pobre se elevó durante el mismo periodo del 12.6\% al 15.6\%. 
Es significativo que numerosos brasileños consideren la disminución del ingreso del $20 \%$ más rico de la población como la desaparición de las clases medias y una polarización de la población brasileña. Efectivamente, el estudio de Rocha y Urani (2007) muestra perfectamente que las categorías más ricas de la población brasileña tienden a declararse entre las más pobres en las encuestas, o por lo menos entre las clases que perciben un ingreso promedio. Asimismo, en el estudio de estos dos autores, el 50\% de las personas del $10 \%$ más rico encuestadas piensan ubicarse entre las cuatro décimas más pobres (mientras que la mayoría del $10 \%$ más pobre estima formar parte de la clase media y que el 5.7\% de los encuestados de esta décima menos favorecida se coloca en las dos décimas más ricas...). De igual manera, un estudio realizado sobre 120 estudiantes de la Universidad Federal de Río de Janeiro (pertenecientes al 10\% más rico de la población) revela que, en su mayoría, piensan que los ingresos mensuales de la clase media se ubican entre 1388 y 5002 reales (cuando tales ingresos sólo conciernen al 5.1\% más rico del país y sólo son superados por el $0.4 \%$ de los salarios) (Rocha y Urani, 2007). La

Gráfica 5. Repartición de la población brasileña, en función del ingreso mensual

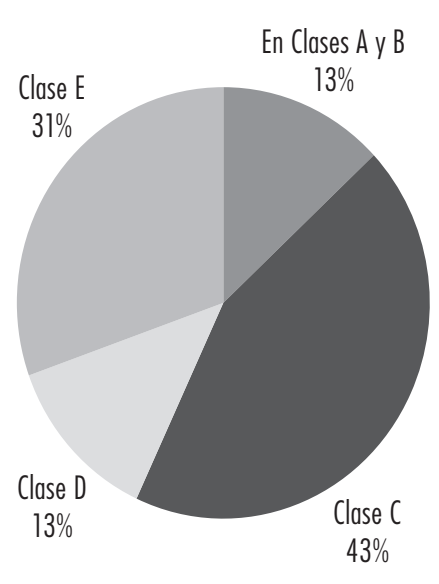

En 2002

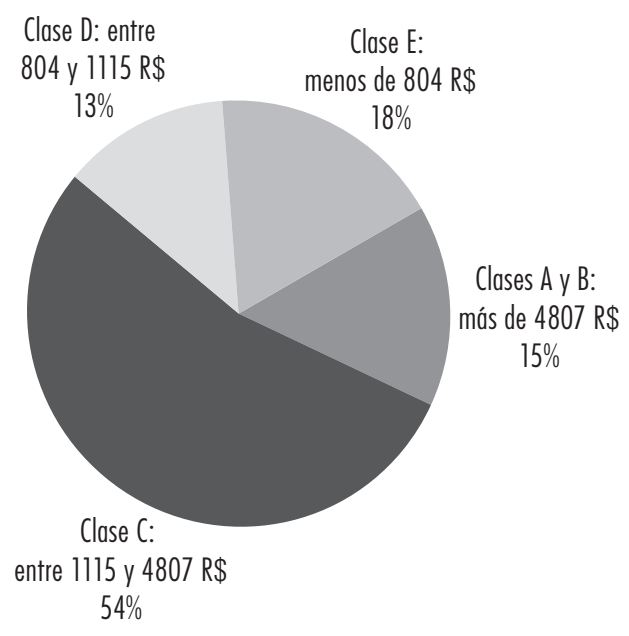

En 2009

Fuente: Fundação Getulio Vargas. 
percepción de las desigualdades en Brasil es por lo tanto particularmente falseada por el hecho de que los brasileńos logran difícilmente ubicarse en la escala de ingresos nacional.

Sin embargo, frente a la innegable disminución de las desigualdades de ingreso y a la emergencia de una nueva clase media, parece difícil hablar de polarización de la sociedad brasileña. Según la Fundación Getulio Vargas, la sociedad brasileña está dividida hoy en día en cinco clases, A, B, C, D y E, y la clase C, que constituye la clase media actual, está en plena expansión, ya que constituye en 2009 el 54\% de la población frente al 43\% en 2002. Esta evolución tiene su principal explicación en el enriquecimiento de los brasileños de la clase $\mathrm{E}$-que pasó del 31\% de la población en 2002 al 18\% en 2009-y de su tránsito hacia la clase $\mathrm{D}$, así como en el ascenso social masivo de numerosas personas durante la última década de la clase D hacia la clase C. La crisis económica mundial desde 2008 no detuvo esta evolución ya que este mismo año, el número de brasileños en la clase c aumentó del $4.13 \%$ mientras que a raíz de la caída de las cotizaciones en la bolsa de valores, la clase A-B se contrajo del $0.65 \%$.

\section{Las oportunidades y los peligros generados por la emergencia de una nueva clase media}

\section{El patrón de consumo de la nueva clase media}

La expansión de la clase c podría estimular en el futuro la economía nacional a través del incremento subsecuente del consumo de los hogares brasileńos. Se estima hoy, por cierto, que el consumo es el principal componente del producto interior bruto brasileño al representar el $60 \%$ de éste, y es probable que sostuviera el crecimiento económico de 2010, en particular el consumo de las clases C, D y e que aumentó del $8 \%$ en ese ańo (frente a un crecimiento del $4 \%$ del consumo de las clases А у в). Sin embargo, al contrario de la tercera demanda del milagro económico, nada asegura que la totalidad de la clase c, que asume el 50\% del consumo brasileño, esté en medida de consumir bienes durables de la más alta tecnología y pueda estimular así la producción de bienes de consumo cuya demanda internacional está en constante aumento (Palma, 2005).

La clase $\mathrm{C}$ no es homogénea, por supuesto, respecto al patrón de consumo de quienes la componen y tapa profundas diferencias en cuanto al acceso a los bienes durables, diferencias que la lectura de las encuestas de consumo del IBGE (Instituto Brasileño de Geografía y Estadísticas) nos revela sin embargo 
totalmente. El IBGE descompone la población brasileña en tres tercios, y evidencia así claramente un consumo de bienes durables mucho mayor en el tercio más rico que en los otros dos. Mientras que entre los que se ubican en este tercio -que reúne las clases А у в junto con menos de la mitad de la clase с y se compone esencialmente de la tercera demanda nacida durante el milagro económico- $89.3 \%$ poseen una lavadora, este porcentaje sólo es del $15.8 \%$ y del 7.4\% respectivamente en los otros dos tercios; de igual forma, el $54.3 \%$ del tercio más rico está equipado con una computadora frente al $9 \%$ y al $3 \%$ para los otros dos. Ahora bien, el 30\% más rico experimenta actualmente una disminución relativa de sus ingresos que no se trasparenta sin embargo en las gráficas reproducidas más arriba, y esta evolución podría poner en peligro el aparato productivo nacional. Ciertamente, se puede contemplar el poco equipamiento de los otros dos tercios como una ventaja para la industria brasileña ya que representa un nuevo mercado que conquistar. Sin embargo, las capacidades financieras de estos hogares aún no les permiten adquirir siempre a corto o mediano plazo bienes cuya compra requiere un fuerte poder adquisitivo, y según Cacciamali y Camillo (2009a), la disminución de las desigualdades en Brasil no es suficiente actualmente para estimular un fuerte consumo entre las categorías más desfavorecidas.

Cuadro 3. Equipamiento en bienes de consumo durables de los hogares brasileños clasificados por rangos de ingreso en 2008

(en \%)

\begin{tabular}{lcccc}
\hline & Ter tercio & 2do tercio & 3er tercio & promedio nacional \\
\hline Congelador & 4,4 & 7,4 & 37,4 & 16,4 \\
Horno & 91,9 & 96,9 & 104,3 & 97,7 \\
Lavadora & 7,4 & 15,8 & 89,3 & 37,5 \\
Computadora & 3 & 9 & 54,3 & 22,1 \\
Radio & 74,5 & 83,2 & 106 & 87,9 \\
Refrigerador & 64 & 83,6 & 96,5 & 89,2 \\
Teléfono fijo & 30,3 & 65,7 & 127,5 & 74,5 \\
Teléfono celular & 22,3 & 44,5 & 124 & 63,6 \\
Televisor & 77,2 & 90,1 & 111,7 & 93 \\
Carro & 5,2 & 14,4 & 80,3 & 33,3 \\
\hline
\end{tabular}

Fuente: BGGE, Pesquisa de Orçamentos Familiares, 2008-2009. 


\section{Los peligros de este nuevo patrón de consumo}

Si bien es cierto que la desindustrialización relativa de Brasil contribuyó a impulsar la disminución de las desigualdades y a la emergencia de una nueva clase media en detrimento de las categorías más ricas, conlleva también el riesgo de estimular la producción de bienes destinados a esta capa social emergente, lo cual incrementaría el desfase entre el bajo nivel tecnológico de la industria brasileńa y la demanda mundial, reforzando por consiguiente el proceso de desindustrialización. Para abundar en este sentido, cabe observar que el déficit comercial para los productos manufacturados fue de 35 billones de dólares en 2010, mientras que había un excedente de 24 billones en 2004: para los productos de alta y de medianamente alta tecnología, la situación es peor aún ya que, en su caso, el déficit es de 65 billones (Gaulard, 2011: 84-85). En 2010, el excedente comercial de Brasil aun alcanzó 20 billones de dólares pero resulta sobre todo del saldo positivo obtenido en el comercio de productos agrícolas y mineros, que constituye el 70\% de este excedente, y se está volviendo siempre más difícil ver al país como una gran potencia industrial competitiva a nivel internacional.

De manera paradoxal, la disminución de las desigualdades no es necesariamente una ventaja para la economía brasileña puesto que, si bien permite ampliar el mercado interior, no es forzosamente en beneficio de las industrias que serían más susceptibles de hacerse un lugar en el escenario internacional (Cacciamali y Camillo, 2009b). Por otra parte, el regreso a un nivel más bajo en la escala industrial conlleva el riesgo de aumentar la competencia en el mercado brasileño entre los productos provenientes de países asiáticos y los productos nacionales que no pueden beneficiarse de un coste de mano de obra tan bajo como en China (se estima hoy que el coste de la mano de obra es cinco veces más bajo en China que en Brasil). Al perder su avance tecnológico, Brasil corre por lo tanto el riesgo de confrontarse a un reforzamiento del proceso de desindustrialización y si bien es cierto que la evolución social del país parece éticamente más justa, eso no la hace sino más peligrosa para el mantenimiento del crecimiento.

Para terminar con una nota optimista, la formación de un amplio mercado interior brasileño puede también desembocar en una sofisticación de la producción de bienes durables si y sólo si Brasil logra mantener un crecimiento suficientemente fuerte para que los ingresos de los dos tercios más pobres de su población les den acceso al consumo de bienes de alto contenido tecnológico. Para ello, sería preciso que la coyuntura internacional no se degrade más, puesto que el crecimiento se vería profundamente perjudicado por una caída de las exportaciones (que constituyen el 15\% del PIB) y una nueva huída de los capitales. 


\section{CONCLUSIÓN}

La estructura del aparato productivo contribuye a explicar en gran parte el carácter más o menos desigualitario de la sociedad brasileña y las políticas sociales del gobierno de Lula, en comparación, desempeñaron un papel menos importante en la disminución reciente del Índice Gini.

Mientras que el peso concedido al trabajo que no requiere capacitación así como la presencia de tasas de interés altas, que benefician a una minoría de la población, generaron un fuerte incremento de las desigualdades hasta mediados de los ańos noventa, estas últimas no han dejado de disminuir desde hace unos quince años. La expansión de sectores poco productivos que emplean una mano de obra sin capacitación y el desarrollo de regiones que siempre habían sido apartadas del proceso de crecimiento, dio origen a la evolución de la estructura social del país. Sin embargo, esta situación no puede ser sostenible puesto que la expansión de estos sectores, relacionados esencialmente con la agricultura, depende de la evolución de las cotizaciones de las materias primas y de la situación económica internacional, siendo ambas cosas profundamente inestables.

Confrontado a los retos que la economía mundial y sus disfuncionamientos amenazan con plantear en el futuro a las grandes potencias emergentes, Brasil podría encontrarse rápidamente desprovisto si no se instaura una nueva y radical transformación de su aparato productivo en los próximos años. Tal evolución hacia una sofisticación de su industria tendía sin embargo a reforzar la estructura desigualitaria del país, como lo revela la trayectoria económica que ha seguido China desde inicios de la década de los ochenta. Por ende, se plantea la cuestión de la compatibilidad entre éxito económico y justicia social, así como de la capacidad del modo de producción actual de satisfacer las necesidades de cada quien.

\section{BIBLIOGRAFÍA}

Boito Junior, Armando, "A burguesia no goberno Lula”, en Eduardo Basualdo, Enrique Arceo (coord.), Neoliberalismo y sectores dominantes, tendencias globales y experiencias nacionales, Buenos Aires, ClACso, 2006.

Bresser Pereira, Luiz Carlos, Desenvolvimento e crise no Brasil, São Paulo, Editora Brasiliense, 1977.

, "The Dutch Disease and its Neutralization: a Ricardian

Approach”, en Revista de Economia Política, vol. 28, № 1, São Paulo, eneromarzo de 2008. 
, Luiz Carlos, Developing Brazil: Overcoming the Failure of the Washington Consensus, Boulder, Lynne Rienner Publishers, 2009.

Cacciamali, Maria Cristina e Vladimir Sipriano Camillo, "Magnitude da queda da desigualdade de renda no Brasil de 2001 a 2006: uma abordagem regional por tipos de renda", Rio de Janeiro, Congreso de LASA, junio de 2009a.

Cacciamali, Maria Cristina e Vladimir Sipriano Camillo, "Redução da desigualdade na distribuição de renda entre 2001 e 2006 nas macrorregiốes brasileiras", Economia e Sociedade, vol. 18, № 2, Campinas, agosto de $2009 \mathrm{~b}$.

Dedecca, Claudio, Adriana Jungbluth, e Cassiano Trovão, "A queda recente da desigualdade: relevância e limites", Salvador, xxxvi Encontro Nacional de Economia, ANPEC, diciembre de 2008.

Gaulard, Mylène, L'Economie du Brésil, Paris, Bréal, 2011.

Hoffmann, Rodolfo, "Transferência de renda e redução da desigualdade no Brasil e em cinco regióes entre 1997 e 2005”, en Barros, Ricardo, Miguel Nathan Foguel e Gabriel Ulyssea, Desigualdade de renda no Brasil: uma análise da queda recente, Brasilia, IPEA, 2007, pp.17-40.

, "Desigualdade da distribuição de renda no Brasil: a contribuição de aposentadorias e pensóes e de outras parcelas de rendimento domiciliar per capita", en Economia e Sociedade, vol. 18, No 1, abril de 2009, pp. 213-231.

IBGE, Pesquisa de Orçamentos Familiares, Rio de Janeiro, 2008-2009.

Kliass, Paulo, Pierre Salama, "La globalisation au Brésil, responsable ou bouc émissaire ?”, en Lusotopie, vol. 14, N² 2, Bordeaux, 2007, pp. 109-132.

Lautier, Bruno, "Les politiques sociales au Brésil durant le gouvernement de Lula: aumône d'Etat ou droits sociaux", en Problèmes d'Amérique Latine, $\mathrm{N}^{\circ}$ 63, Paris, invierno 2006-2007, pp. 51-76.

Marques, Rosa Maria, Paulo Nakatani, "La politique du gouvernement Lula: changement ou continuité ?", en Revue Tiers Monde $\mathrm{N}^{\circ} 189$, Nogent-SurMarne, enero-marzo de 2007.

Mesquita Moreira, Mauricio, "Fear of China: is There a Future for Manufacturing in Latin America", en World Development, vol. 35, $\mathrm{N}^{\circ} 3$, Montreal, marzo de 2006, pp. 355-376.

Nassif, André, "Há evidências de desindustrialização no Brasil", en Revista de Economia Política, vol. 28, № 1, São Paulo, enero-marzo de 2008.

Neri, Marcelo, "Miseria, desigualdade e politicas de rendas", Rio de Janeiro, Fundação Getulio Vargas, 10 de septiembre de 2007.

Oman, Charles, Quelles politiques pour attirer les investissements directs étrangers?, Paris, Études du Centre de Développement, OCDE, 2000. 
Oreiro, José Luis, Carmem Feijó, "Desindustrialização: conceituação, causas, efeitos e o caso brasileiro", en Revista de Economia Politica, vol. 30, № 2, São Paulo, abril-junio de 2010.

Paes de Barros, Ricardo, Mirela de Carvalho, Samuel Franco, Rosane Mendonça, "A queda recente da desigualdade de renda no Brasil", IPEA, Texto para Discussão $\mathrm{N}^{\circ} 1258$, Rio de Janeiro, enero de 2007a.

Paes de Barros, Ricardo, Samir Cury, Gabriel Ulyssea, "A desigualdade de renda no Brasil encontra-se subestimada? Uma análise comparativa com base na PNAD, na POF e nas contas nacionais", IPEA, Texto para Discussão $\mathrm{N}^{\circ} 1263$, Rio de Janeiro, marzo de 2007b.

Paes de Barros, Ricardo, Samuel Franco, Rosane Mendonça, "Discriminação e segmentação no mercado de trabalho e desigualdade de renda no Brasil", IPEA, Texto para Discussáo No 1288, Rio de Janeiro, julio de 2007c.

Paes de Barros, Ricardo, Mirela de Carvalho, Samuel Franco, Rosane Mendonça, "Determinantes da queda na desigualdade de renda no Brasil", IPEA, Texto para Discussão, № 1460, Rio de Janeiro, enero de 2010.

Palma, Gabriel, Flying-Geese and Waddling-Ducks: the Different Capabilities of East Asia and Latin America to 'Demand-Adapt' and 'Supply-upgrade' Their Export Productive Capacity, University of Cambridge, febrero de 2005.

Pochmann, Marcio, Ricardo Amorim, Atlas da exclusão social no Brasil, São Paulo, Cortez Editora, 2003.

Pochmann, Marcio, "Desigualdade e justiça tribútaria", Brasilia, IPEA, 15 de mayo de 2008.

Rocha, Sonia, "Transferts de revenus et pauvreté au Brésil”, en Revue TiersMonde, Nogent-sur-Marne, № 205, marzo de 2011, pp. 191-210.

Rocha, Runi, André Urani, "Posicionamento social e a hipótese da distribuição de renda desconhecida", en Revista de Economia Política, vol. 27, № 4, São Paulo, octubre-diciembre de 2007, pp. 595-615.

Salm, Claudio, "Sobre a recente queda da desigualdade de renda no Brasil: uma leitura crítica", Rio de Janeiro, Centro Celso Furtado, 2007.

Serra, José, Desenvolvimento capitalista no Brasil, São Paulo, Editora Brasiliense, 1982.

Soares, Sergei, "Programas de tranferência condicionada de renda no Brasil, Chile e México : impactos sobre a desigualdade", IPEA, Texto para Discussão, $\mathrm{N}^{\circ}$ 1293, Rio de Janeiro, julio de 2007.

Théry, Hervé, Le Brésil, Paris, Armand Colin, 2005. 